\title{
Cost-effectiveness analysis of N95 respirators and medical masks to protect healthcare workers in China from respiratory infections
}

\author{
Shohini Mukerji ${ }^{1 *}$ (D, C. Raina Maclntyre ${ }^{1,2}$, Holly Seale ${ }^{1}$, Quanyi Wang ${ }^{3}$, Peng Yang ${ }^{3}$, Xiaoli Wang ${ }^{3}$
} and Anthony T. Newall ${ }^{1}$

\begin{abstract}
Background: There are substantial differences between the costs of medical masks and N95 respirators. Costeffectiveness analysis is required to assist decision-makers evaluating alternative healthcare worker (HCW) mask/ respirator strategies. This study aims to compare the cost-effectiveness of N95 respirators and medical masks for protecting HCWs in Beijing, China.

Methods: We developed a cost-effectiveness analysis model utilising efficacy and resource use data from two cluster randomised clinical trials assessing various mask/respirator strategies conducted in HCWs in Level 2 and 3 Beijing hospitals for the 2008-09 and 2009-10 influenza seasons. The main outcome measure was the incremental cost-effectiveness ratio (ICER) per clinical respiratory illness (CRI) case prevented. We used a societal perspective which included intervention costs, the healthcare costs of CRI in HCWs and absenteeism costs.

Results: The incremental cost to prevent a CRI case with continuous use of N95 respirators when compared to medical masks ranged from US \$490-\$1230 (approx. 3000-7600 RMB). One-way sensitivity analysis indicated that the CRI attack rate and intervention effectiveness had the greatest impact on cost-effectiveness.

Conclusions: The determination of cost-effectiveness for mask/respirator strategies will depend on the willingness to pay to prevent a CRI case in a HCW, which will vary between countries. In the case of a highly pathogenic pandemic, respirator use in HCWs would likely be a cost-effective intervention.
\end{abstract}

Keywords: Cost-effectiveness, Economic evaluation, N95 respirator, Mask, Healthcare worker

\section{Background}

Healthcare workers (HCWs) are at increased risk of contracting influenza and other respiratory infections compared to the rest of the adult working population [1]. The use of respirators and masks to reduce transmission of these infections within hospitals can decrease the costs associated with $\mathrm{HCW}$ absenteeism and the costs of nosocomial infections in vulnerable patients. Mask/respirator availability can also be crucial in the context of emerging respiratory infection threats to

\footnotetext{
* Correspondence: s.mukerji@unsw.edu.au

${ }^{1}$ School of Public Health and Community Medicine, The University of New South Wales, Sydney, NSW 2052, Australia

Full list of author information is available at the end of the article
}

HCWs where effective pharmaceutical interventions may not be available, e.g. the 2003 severe acute respiratory syndrome (SARS) epidemic and the Middle East Respiratory Syndrome (MERS) outbreaks since 2012 [2, 3].

Medical masks, referred to as surgical masks in some countries [4], were not designed to protect the wearer from aerosol transmission of droplet nuclei and viral particles [5, 6]. Respirators are specially engineered for this purpose [7]. The N95 respirator models have been tested and proven to have at least $95 \%$ particle filter efficiency [8]. The World Health Organization (WHO) and the U.S. Centres for Disease Control and Prevention (CDC) recommend the use of a mask in low-risk settings and a respirator in high-risk settings (e.g. during 
aerosol generating procedures) to protect healthcare workers (HCWs) from seasonal influenza $[9,10]$. In the context of influenza $\mathrm{A}(\mathrm{H} 1 \mathrm{~N} 1)$ pdm09, the WHO recommended similar precautions to those advised for seasonal influenza while the CDC recommended at least the equivalent of a fit tested N95 respirator for HCWs in contact with pandemic influenza patients, even when aerosol-generating procedures were not being conducted $[11,12]$.

There are substantial differences between the costs of respirators and masks that may affect the development of country specific mask/respirator guidelines for HCWs [4]. Another potentially important consideration is fit testing, which adds to the cost of respirator use, but may help ensure the seal of a respirator to a HCW's face [7]. A recent review identified the lack of economic evaluations that used clinical efficacy estimates to assess the cost-effectiveness of mask/respirator use in healthcare settings [13]. The aim of this present study is to compare the cost-effectiveness of respirator and mask interventions in HCWs using data from two large clinical trials conducted in Beijing hospitals [14, 15].

\section{Methods}

\section{Trial and intervention design}

The two previously published cluster randomised trials used in this economic evaluation $[14,15]$ were designed to measure the efficacy of N95 respirators and medical masks to protect HCWs from respiratory infections in Beijing hospitals. In these trial designs, the units of randomisation were entire emergency departments or respiratory wards from Level 2 and 3 hospitals, assigned to each intervention. The participants were the HCWs working in each of the enrolled wards, i.e., all nurses, doctors and administration staff. These wards were selected as they were considered to be high-risk settings for occupational exposure to respiratory infections. The intervention period in the first trial (Trial 1) was during the winter of 2008/09, from December 2008 to January 2009 [14]. The second trial (Trial 2) intervention period followed in the winter of 2009/10, from December 2009 to January 2010 [15].

In Trial 1 continuous use of fit tested and non-fit tested N95 respirators was compared to medical masks [14]. Continuous use referred to the wearing of N95 respirators or medical masks for the entire shift. It was deemed unethical to randomise wards to a control arm (i.e. no mask use), so a convenience sample of HCWs from hospitals with documented pre-study low rates of mask use was recruited. This arm was excluded from this economic analysis due to the lack of randomisation. In Trial 2 there were two fit tested N95 respirator arms and the difference between these arms was that one arm employed continuous respirator use while the other carried out targeted (i.e. selective) respirator use by HCWs only whilst conducting high-risk procedures such as common aerosol-generating procedures, or when barrier nursing patients with known respiratory illness. These arms were compared to a continuous use medical mask arm (as used in Trial 1).

In Trial 1, the number of HCWs per arm was 492, 461 and 488 for the continuous medical mask, continuous N95 fit tested and continuous N95 non-fit tested arms respectively. In Trial 2, the number of HCWs per arm was 572,516 and 581 for the continuous medical mask, targeted N95 fit tested and continuous N95 fit tested arms respectively. The criterion for clinical respiratory illness (CRI) in both trials was the presentation of two or more respiratory symptoms or one respiratory symptom and one systemic symptom [14, 16]. Respiratory symptoms considered were cough, nasal congestion, rhinorrhoea, sore throat and sneezing. Systemic symptoms considered were a temperature $>38{ }^{\circ} \mathrm{C}$, perceived chills and/or fever, lethargy, loss of appetite and myalgia.

The respirators and masks used in both trials were sourced from the manufacturer $3 \mathrm{M}$ China $[14,15]$. As the models supplied in Trial 1 had been discontinued for China by the following season, different models of the same respirator and mask types were supplied in Trial 2. Both trials included at least one arm that applied qualitative fit testing for participating $\mathrm{HCW}$ s once at the beginning of the trial period, according to the manufacturer's instructions [17].

\section{Perspectives}

We adopted a societal perspective, as recommended by the WHO cost-effectiveness analysis guidelines [18]. We included the costs for the interventions in addition to inpatient and outpatient costs to the healthcare system for HCW CRI cases. Indirect (productivity) costs were included for $15 \mathrm{~min}$ of staff time lost while being fit tested for respirators and due to $\mathrm{HCW}$ absenteeism for CRI. The only out-of-pocket costs included were the costs of medications and outpatient visits to healthcare centres/fever clinics and emergency wards for CRI. Other potential out-of-pocket costs incurred to HCWs with CRI, such as healthcare co-payments and direct non-medical costs (e.g. transport costs) were excluded as no trial data was collected on these items.

\section{Economic model design}

We applied a decision analytic model using Microsoft Excel to construct a separate economic evaluation for each trial. Costs and health outcomes were not discounted as the time horizon of the analysis was less than one year ( 28 days). The primary outcome was the incremental cost effectiveness ratio (ICER) per CRI case prevented. This was chosen as CRI in HCWs was the 
primary endpoint in both trials (CRI cases in patients were not recorded). A one-way sensitivity analysis was carried out on a range of parameters to identify those that most substantially impacted on the ICER. In scenario analysis we examined seasonal variation in attack rates for CRI (from 1-30\%) [1] to capture values outside of those observed in the years the trials were run.

Before adjusting for confounding, Trial 1 found that only the continuous use non-fit tested N95 arm was significantly more protective against CRI than medical masks [14]. However, a combined 'All N95' arm, which included both fit tested and non-fit tested N95 groups (there was no significant difference between these groups), was found to be significantly more protective in post-hoc cluster confounder adjusted analysis compared to medical masks [14]. For these reasons, we calculated our ICER results for this trial using the efficacy estimated for this 'All N95' arm. However, to explore the impact of fit testing on cost-effectiveness, we selectively either included/excluded the cost of fit testing for those in the 'All N95' arm. For Trial 2, after the results were cluster and confounder adjusted, only the continuous use fit tested N95 arm had a significantly more protective effect compared to medical masks [15]. We excluded the targeted use fit tested $\mathrm{N} 95$ arm from the economic analysis as there was no significant difference in results for this arm when compared to medical masks [15].

\section{Parameter input sources}

The CRI rates observed in each of the arms of the trials were used when reporting preliminary results for all arms, however when estimating ICERs, CRI rates were generated from the intention-to-treat cluster and confounder adjusted significant efficacy results from both trials $[14,15]$. Information on intervention efficacy, the number of respirators or masks used per shift and shift durations, were obtained from the trial publications $[14,15]$. Data on $\mathrm{HCW}$ resource use due to CRI cases, the exact proportions of each staff type in each arm, the number of shifts worked and the number of days of leave taken, were extracted from the trial databases. Healthcare resource use costs for treatments were sourced from the Beijing pharmaceutical sunshine procurement platform [19]. Estimates were used for the costs of visits to healthcare centres or emergency departments and staff monthly salary costs (Xiaoli Wang, Beijing CDC, personal communication, July 2014). The estimated salary costs were comparable (approximately) with the National Bureau of Statistics China average health and social work salary for 2014 [20]. Costs are reported in 2014 US Dollars and 2014 Chinese Renminbi using the exchange rate of $1 \mathrm{USD}=6.2 \mathrm{RMB}$ (Table 1).

\section{Costs of intervention}

For both trials separately, respirator and mask costs per $\mathrm{HCW}$ for each arm were calculated by multiplying the mean number of shifts worked in the 28 day trial periods, by the cost of either two N95 respirators or three medical masks as provided per $\mathrm{HCW}$ for each shift worked in the trials $[14,15]$. HCWs worked an average of 20 shifts in Trial 1 and 22 shifts in Trial 2 over the trial duration, with a typical shift being eight hours in duration.

For fit tested arms, the mean cost of 15 min of HCW time to be fit tested was included, taking into account the proportion of each staff type (doctors, nurses, etc.) in the trial. Fit tester time was included as the cost of 15 min of an administration staff member's time per HCW, US \$1.98 (12 RMB) in Trial 1 and US \$1.81 (11 $\mathrm{RMB}$ ) in Trial 2. This cost (calculated from monthly salaries) was estimated to be different between the trials as HCWs worked slightly more shifts per month on average in Trial 2. As test operators can be self-taught we did not include any training costs [17]. The respirator, mask and fit test kit costs applied are shown in Table 1 (models from $3 \mathrm{M}$ China: $3 \mathrm{M}$ flat-fold N95 respirator [catalogue number 9132], 3 M Standard TieOn Surgical Mask [catalogue number mask 1817], and 3 M FT-30 Bitrex Fit Test Kit). The mean cost of a fit test kit applied to each HCW was calculated by multiplying the number of wards in the arm by the cost of a kit, and dividing this by the total number of HCWs in that respective arm. This simulated the likely occurrence that in practice one fit test kit would be purchased for each hospital ward conducting fit testing (Xiaoli Wang, Beijing CDC, personal communication, July 2014).

\section{Cost of CRI}

Information on the direct healthcare resource use of each HCW who was documented as having a CRI during the trials was collected through surveys completed in person. HCWs who had symptoms were required to report to the ward head nurse for survey completion. This provided data on the different types of treatment used by the HCW for a specific CRI episode and on the number of healthcare centre/fever clinic visits and emergency ward visits. This was used to calculate the mean cost of CRI for a HCW in each trial.

Indirect costs, in terms of productivity loss due to HCWs taking leave for a CRI episode, were estimated using the human capital approach [21]. The mean leave cost per HCW with CRI in each trial was calculated taking into account the proportions of each staff type that took leave. The productivity cost per day of leave was calculated by dividing mean monthly income by the average number of shifts for all HCWs in the 28 days trial period (i.e. 20 shifts in Trial 1 and 22 in Trial 2). 
Table 1 Unit costs associated with intervention strategies in Beijing hospitals for the 2008-09 and 2009-10 influenza seasons

\begin{tabular}{|c|c|c|}
\hline Parameters & $\begin{array}{l}\text { Base case value } \\
\text { (2014 USD, Chinese RMB) }\end{array}$ & Source \\
\hline \multicolumn{3}{|l|}{ Equipment costs ('list price' per unit) ${ }^{a}$} \\
\hline Medical mask & $0.14(1)$ & $\begin{array}{l}3 \mathrm{M} \text { China, } 3 \text { M Standard Tie-On Surgical } \\
\text { Mask (catalogue number mask 1817) }\end{array}$ \\
\hline N95 respirator & $0.79(5)$ & 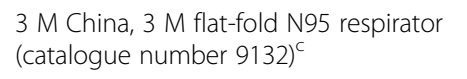 \\
\hline Fit Test Kit & $608(3770)$ & 3 M China, 3 M FT-30 Bitrex Fit Test Kit ${ }^{c}$ \\
\hline \multicolumn{3}{|l|}{ Productivity cost of HCW time to be fit tested ${ }^{d}$} \\
\hline Doctor & $\begin{array}{l}2.48(15) \text { Trial } 1 \\
2.26(14) \text { Trial } 2\end{array}$ & $\begin{array}{l}\text { Calculated based on estimated monthly } \\
\text { staff salaries }\end{array}$ \\
\hline Nurse & $\begin{array}{l}1.74(11) \text { Trial } 1 \\
1.58(10) \text { Trial } 2\end{array}$ & $\begin{array}{l}\text { Calculated based on estimated monthly } \\
\text { staff salaries }\end{array}$ \\
\hline Administration staff & $\begin{array}{l}1.98(12) \text { Trial } 1 \\
1.81(11) \text { Trial } 2\end{array}$ & $\begin{array}{l}\text { Calculated based on estimated monthly } \\
\text { staff salaries }\end{array}$ \\
\hline \multicolumn{3}{|c|}{ Unit costs associated clinical respiratory illness (CRI) } \\
\hline \multicolumn{3}{|l|}{ Direct costs } \\
\hline Antibiotics (e.g. Azithromycin 6 tablets) & $1.93(12)$ & $\begin{array}{l}\text { Beijing pharmaceutical sunshine } \\
\text { procurement platform [19] }\end{array}$ \\
\hline $\begin{array}{l}\text { Antitussives (e.g. Apricot cough syrup } \\
250 \mathrm{ml} \text { bottle) }\end{array}$ & $4.03(25)$ & $\begin{array}{l}\text { Beijing pharmaceutical sunshine } \\
\text { procurement platform [19] }\end{array}$ \\
\hline $\begin{array}{l}\text { Antipyretics (e.g. Paracetamol } 12 \\
\text { tablets) }\end{array}$ & $1.45(9)$ & $\begin{array}{l}\text { Beijing pharmaceutical sunshine } \\
\text { procurement platform [19] }\end{array}$ \\
\hline Antivirals (e.g. Oseltamivir 10 tablets) & $35.65(221)$ & $\begin{array}{l}\text { Beijing pharmaceutical sunshine } \\
\text { procurement platform [19] }\end{array}$ \\
\hline $\begin{array}{l}\text { Traditional. Chinese Medicine } \\
\text { (e.g. Ganmao Qingre Granules) } 10 \text { bags }\end{array}$ & $1.93(12)$ & $\begin{array}{l}\text { Beijing pharmaceutical sunshine } \\
\text { procurement platform [19] }\end{array}$ \\
\hline $\begin{array}{l}\text { Healthcare centre/fever clinic/hospital } \\
\text { outpatient visit }^{f}\end{array}$ & $8.06(50)$ & Estimate ${ }^{\mathrm{e}}$ \\
\hline Emergency ward visit $^{\dagger}$ & $16.12(100)$ & Estimate $^{\mathrm{e}}$ \\
\hline \multicolumn{3}{|l|}{ Monthly staff salaries ${ }^{\mathrm{e}}$} \\
\hline Doctor & $1613(10000)$ & Estimate $^{g}$ \\
\hline Nurse & $1129(7000)$ & Estimate $^{\mathrm{g}}$ \\
\hline Administration & $1290(8000)$ & Estimate $^{\mathrm{g}}$ \\
\hline
\end{tabular}

${ }^{2}$ The 'list price' costs for large, health based orders within China (in its economic and taxation framework)

b(Terry Gorman, 3 M Senior Occupational Hygienist, personal communication, January 2012). The 2012 cost for medical mask was used as no updated cost was made available at the time of enquire

'(Terry Gorman, 3 M Senior Occupational Hygienist, personal communication, September 2014)

${ }^{\mathrm{d}}$ Staff time productivity costs for an estimated 15 min of fit testing (based on monthly salary) differs between Trial 1 and 2 due to the slightly greater number of shifts worked per month by HCWs in Trial 2

e(Xiaoli Wang, Beijing CDC, personal communication, July 2014)

${ }^{\mathrm{f} E s t i m a t e d}$ costs for Beijing level 2 hospitalisations were applied in the model

${ }^{9}$ Salary estimates were comparable (approximately) with the average Beijing health and social work salary for 2014 [20]

\section{CRI rates}

In Trial 1 the CRI attack rates for those allocated to continuous N95 use were $4.6 \%$ and $3.3 \%$ (with/without fit testing respectively) and $6.7 \%$ for those allocated to the medical mask use arm (Table 2) [14]. In Trial 2, the CRI attack rate was $7.2 \%$ for those allocated to fit tested N95 respirators compared to $17.1 \%$ for those allocated to the medical mask use arm (Table 2) [15]. These were also compared to a CRI attack rate of $11.8 \%$ for the targeted use fit tested N95 arm in Trial 2 [15], which was excluded from further analysis due to lack of statistical difference compared to the medical mask arm.

\section{Results}

\section{Estimated mean intervention costs}

Intervention costs per $\mathrm{HCW}$ in Trial 1 for the 28 days were US \$32.07 (199 RMB) in the continuous use nonfit tested N95 arm. They were nearly two-fold higher for the continuous use N95 fit tested arm at US \$60.40 (374 
Table 2 Clinical respiratory illness (CRI) and average costs per HCW in each intervention arm for Beijing Trial 1 (2008/09) and Trial 2 (2009/10)

Clinical respiratory illness (CRI) and average costs per HCW in each intervention arm in Trial 1 (Beijing 2008/09) with the adjusted estimate for All N95 combined shown in bold

\begin{tabular}{|c|c|c|c|c|c|}
\hline & $\begin{array}{l}\text { Continuous } \\
\text { medical mask, } \\
2014 \text { USD, } \\
\text { (RMB) }\end{array}$ & $\begin{array}{l}\text { Continuous N95 } \\
\text { non-fit tested } \\
2014 \text { USD, (RMB) }\end{array}$ & $\begin{array}{l}\text { Continuous } \\
\text { N95 fit tested } \\
2014 \text { USD, } \\
\text { (RMB) }\end{array}$ & $\begin{array}{l}\text { Continuous All N95 } \\
\text { (without fit testing cost) } \\
2014 \text { USD, (RMB) }\end{array}$ & $\begin{array}{l}\text { Continuous All N95 } \\
\text { (with fit testing cost) } \\
2014 \text { USD, (RMB) }\end{array}$ \\
\hline CRI \% & $6.7 \%$ & $3.3 \%$ & $4.6 \%$ & $2.6 \%^{a}$ & $2.6 \%^{a}$ \\
\hline $\begin{array}{l}\text { Estimated cases prevented per } 1000 \\
\text { HCWs compared to medical mask }\end{array}$ & NA & 34 & 22 & $41^{\mathrm{a}}$ & $41^{\mathrm{a}}$ \\
\hline Intervention costs per HCW & $8.53(53)$ & 32.07 (199) & $60.40(374)$ & 32.07 (199) & $60.40(374)$ \\
\hline CRI costs per HCW & $0.81(5)$ & $0.39(2)$ & $0.64(4)$ & $0.31(2)$ & $0.31(2)$ \\
\hline Total costs per HCW & $9.34(58)$ & $32.46(201)$ & $61.04(378)$ & $32.48(201)$ & $60.72(376)$ \\
\hline \multicolumn{6}{|c|}{$\begin{array}{l}\text { Clinical respiratory illness (CRI) and average costs per HCW in each intervention arm in Trial } 2 \text { (Beijing 2009/10) with the adjusted estimate for } \\
\text { continuous N95 fit tested shown in bold }\end{array}$} \\
\hline & $\begin{array}{l}\text { Continuous } \\
\text { medical mask } \\
2014 \text { USD, } \\
\text { (RMB) }\end{array}$ & $\begin{array}{l}\text { Targeted N95 fit } \\
\text { tested } \\
2014 \text { USD, (RMB) }\end{array}$ & $\begin{array}{l}\text { Continuous } \\
\text { N95 fit tested } \\
2014 \text { USD, } \\
\text { (RMB) }\end{array}$ & \multicolumn{2}{|l|}{$\begin{array}{l}\text { Continuous N95 fit } \\
\text { tested } \\
2014 \text { USD, (RMB) }\end{array}$} \\
\hline CRI \% & $17.1 \%$ & $11.8 \%$ & $7.2 \%$ & \multicolumn{2}{|l|}{$6.7 \%^{b}$} \\
\hline $\begin{array}{l}\text { Estimated cases prevented per } 1000 \\
\text { HCWs compared to medical mask }\end{array}$ & NA & 53 & 99 & \multicolumn{2}{|l|}{$105^{\mathrm{b}}$} \\
\hline Intervention costs per HCW & $9.35(58)$ & $61.31(380)$ & $61.31(380)$ & \multicolumn{2}{|l|}{$61.31(380)$} \\
\hline CRI costs per HCW & $1.40(9)$ & $0.97(6)$ & $0.59(4)$ & \multicolumn{2}{|l|}{$0.55(3)$} \\
\hline Total costs per HCW & $10.75(67)$ & $62.28(386)$ & $61.90(384)$ & \multicolumn{2}{|l|}{$61.86(384)$} \\
\hline
\end{tabular}

Results calculated based on the clustering and confounder adjusted odds ratio (0.38) for All N95 compared to medical mask (equivalent to a $62 \%$ efficacy $=1$ - OR) ${ }^{\mathrm{b}}$ Results calculated based on the clustering and confounder adjusted hazard ratio (0.39) for continuous $\mathrm{N} 95$ fit tested compared to medical mask (equivalent to a $61 \%$ efficacy $=1-H R)$

RMB) and were US\$8.53 (53 RMB) for the medical mask arm (Table 2). Results for Trial 2 were similar, with intervention costs per HCW of US\$61.31 (380RMB) for both N95 arms and US \$9.35 (58 RMB) per HCW for the medical mask use arm (Table 2).

\section{Estimated mean CRI costs}

The mean CRI costs per HCW case were low in all arms compared to intervention costs (Table 2). The most commonly reported treatment used by those with CRI in both trials (56\% in Trial 1 and 30.5\% in Trial 2) was traditional Chinese medicines (commonly Ganmo Qingre Granules, US $\$ 1.93$ [12 RMB]). A breakdown of mean CRI costs per $\mathrm{HCW}$ and mean intervention costs per $\mathrm{HCW}$ for respective trial intervention arms is shown in Fig. 1.

Mean direct healthcare costs per HCW with CRI in Trial 1 were higher (US \$5.45 [34 RMB]) than in Trial 2 (US \$2.60 [16 RMB]). Mean indirect costs per HCW with CRI were similar between the trials at US \$6.53 (40 RMB) in Trial 1 and US \$5.56 (34 RMB) in Trial 2.

\section{ICER}

The cost-effectiveness estimates described below are focused around the intention-to-treat trial efficacy results for N95 respirators which showed a significant protective effect against CRI, when compared to medical masks, after adjusting for clustering and confounding (shown in bold in Table 2).

\section{Continuous use of fit tested $\mathrm{N} 95$ respirators vs. medical masks}

In Trial 1, when we included the cost of fit testing, the ICER for continuous N95 respirator use was US \$1224 (7589 RMB) per CRI case prevented when compared to medical mask use. In Trial 2 the ICER was US \$489 (3032 RMB) for continuous fit tested N95 respirator use when compared to medical mask use. The difference between the trials is primarily explained by the higher CRI attack rates in Trial 2 (Table 2).

\section{Continuous use of non-fit tested N95 respirators vs. medical masks}

In Trial 1, when we excluded the cost of fit testing, the ICER for continuous N95 respirator use was US $\$ 549$ (3404 RMB) per CRI case prevented when compared to medical mask use. In response to the relatively low fit test failures observed in both trials of $1.1-2.6 \%$ [14, 15], we 


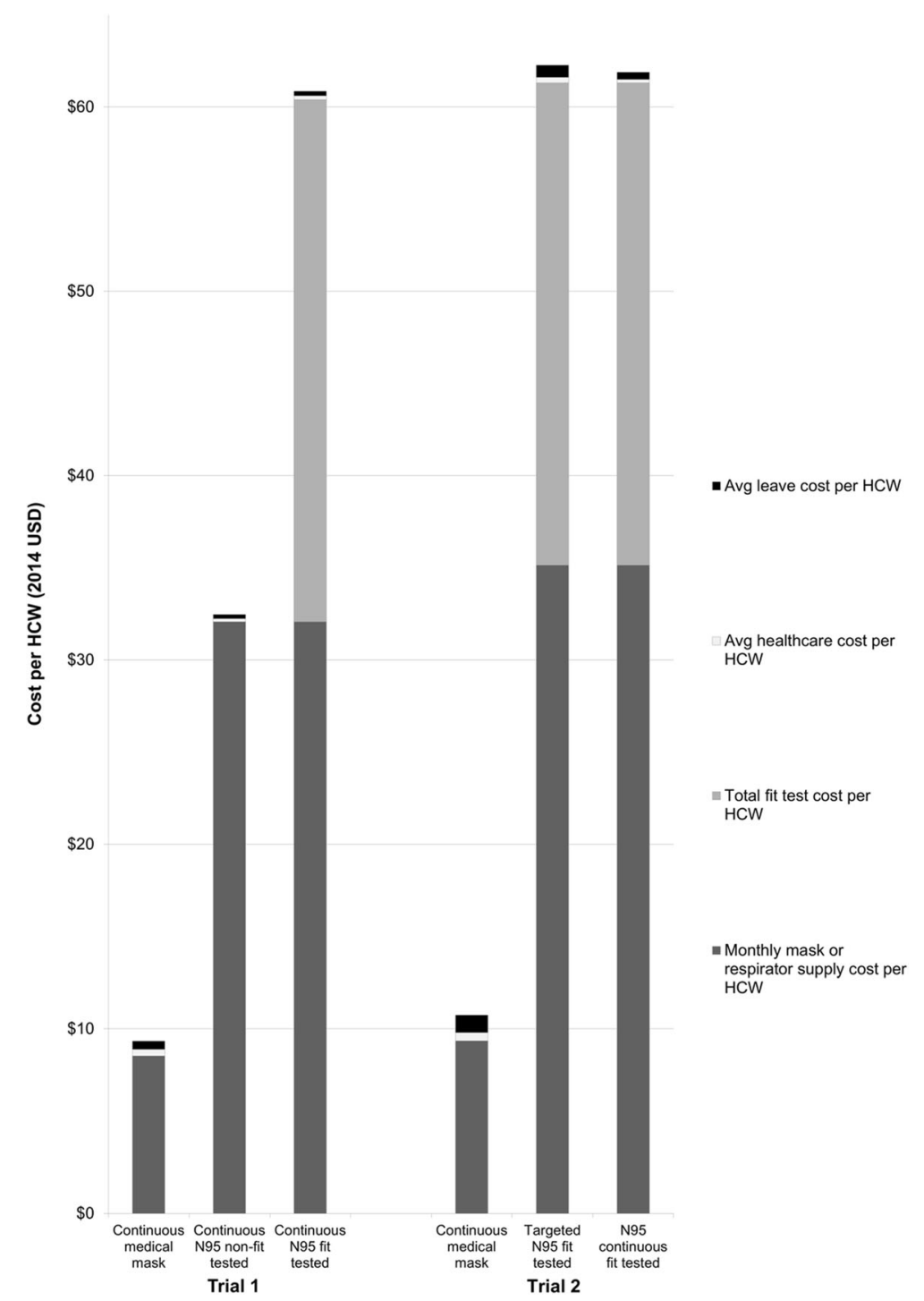

Fig. 1 Average costs per healthcare worker (HCW) in Beijing Trial 1 (2008/09) and Trial 2 (2009/10). The shaded sections within each bar represent different components of the average intervention and treatment costs per HCW for the 28 day period in each trial arm

also estimated the ICER for Trial 2 under a hypothetical scenario where the cost of fit testing was excluded from the respirator arm. This scenario analysis resulted in an ICER for continuous N95 use of US \$239 (1482 RMB) per CRI case prevented compared to medical masks.

\section{Sensitivity analysis results}

One-way sensitivity analysis indicated that CRI attack rate and intervention effectiveness have the greatest impact on the ICERs (Fig. 2). In scenarios where we assumed the attack rate was greater than approximately $4 \%$ for continuous non-fit tested respirators and $8 \%$ for fit tested respirators, the ICERs were below US $\$ 1000$ (6200 RMB) per CRI case prevented (see Fig. 3). The importance of the attack rate is also shown by the overlap in the Trial 1 and 2 results for the N95 continuous fit tested arms when we modelled the same background CRI attack rate in the medical mask arm (see Fig. 3).

In both trials the ICER worsened substantially when the lower effectiveness values from the trial confidence intervals were applied (see Table 3 and Fig. 2). Sensitivity analysis was also carried out on costs for treatment including healthcare visits and the impact of doubling and halving the cost of N95 respirators (see Table 3 and Fig. 2). The potential for the interventions to be cost-saving was only estimated when we assumed a severe illness treatment cost for each CRI case (US \$525, 3255 RMB) [22]. This is an extreme scenario and is unlikely except in a highly pathogenic influenza epidemic/pandemic where a mean case requires substantial healthcare treatment. 
Trial 1 - Continuous All N95 (with fit testing cost) vs Medical Mask

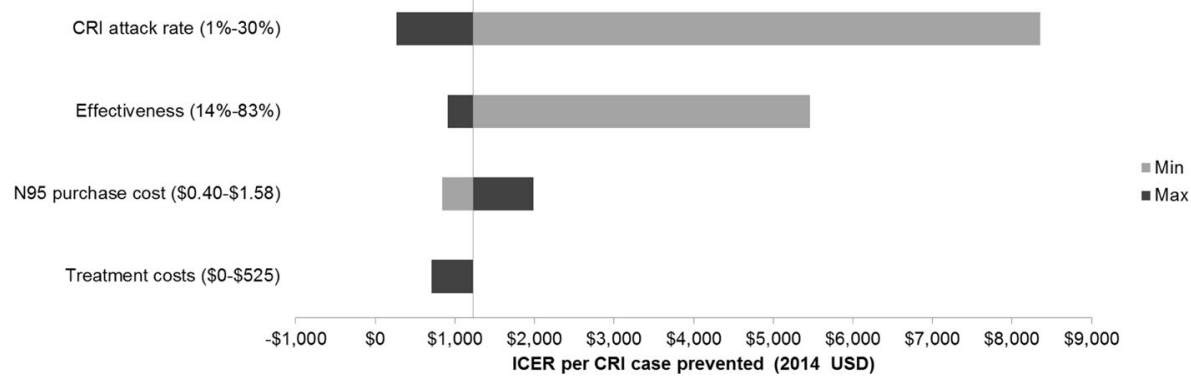

Trial 1 - Continuous All N95 (without fit testing cost) vs Medical Mask

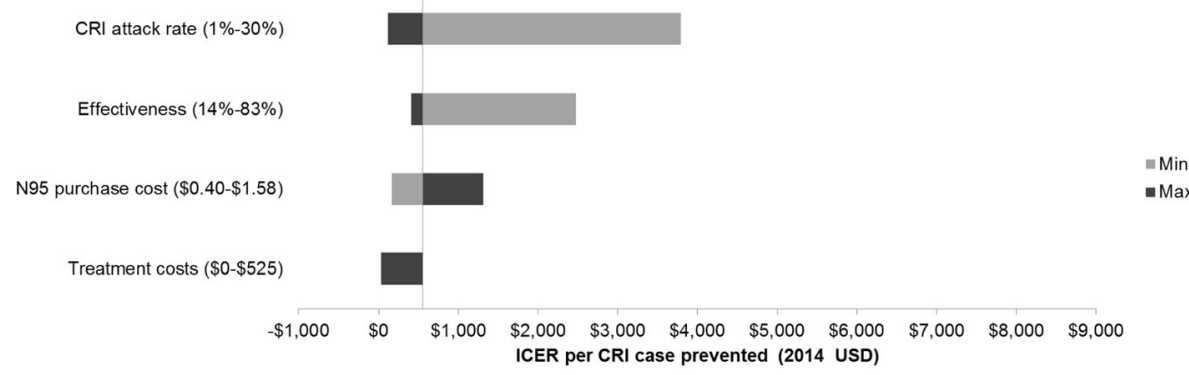

Trial 2 - Continuous N95 fit tested vs Medical Mask

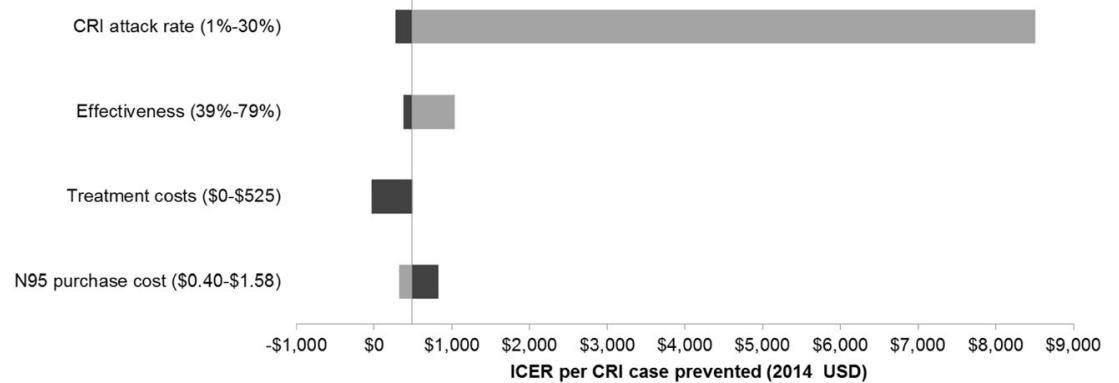

Fig. 2 One-way sensitivity analysis of key parameters on the incremental cost-effectiveness ratio (ICER) per CRI case prevented in Beijing Trial 1 (2008/09) and Trial $2(2009 / 10)$

\section{Discussion}

We estimated that the incremental cost to prevent a CRI case in a HCW for continuous N95 respirator interventions compared to medical masks ranged from US $\$ 490-\$ 1230$ (3000-7600 RMB) in this setting, which is in the acceptable range. We found that including fit testing in a N95 respirator intervention approximately doubles the cost of the intervention and substantially decreases the cost-effectiveness per CRI case prevented compared to medical masks during seasons with a low CRI attack rate. However, these results must be interpreted with caution as the low respirator fit test failure rates $(1.1-2.6 \%)$ observed in the trials may be specific to the N95 respirator models used in both trials [14, 15]. A potential policy option could be to forego fit testing if respirators with known low fit test failure rates were used (such as those used in the trials), although this decision requires careful consideration and would depend on the severity of circulating pathogens. This incremental approach to considering the additional costs and benefits of fit testing may be particularly important in settings where resources are limited and choices must be made between fit testing and other potential lifesaving interventions. At present there is insufficient literature to support that the low failure rates seen in the trials would apply for all respirator models.

We also found that variation in the CRI attack rate was a major factor in determining the cost-effectiveness of respirators (see Fig. 2). The higher attack rate in Trial 2 was most likely due to the more active influenza season observed in the 2009/10 influenza season [14, 15]. The incidence and severity of CRI cases which occur in any given year will vary in accordance with the transmissibility and pathogenicity of the annual influenza strains that are circulating during that season. The incremental cost per CRI case prevented for continuous use N95 respirators 


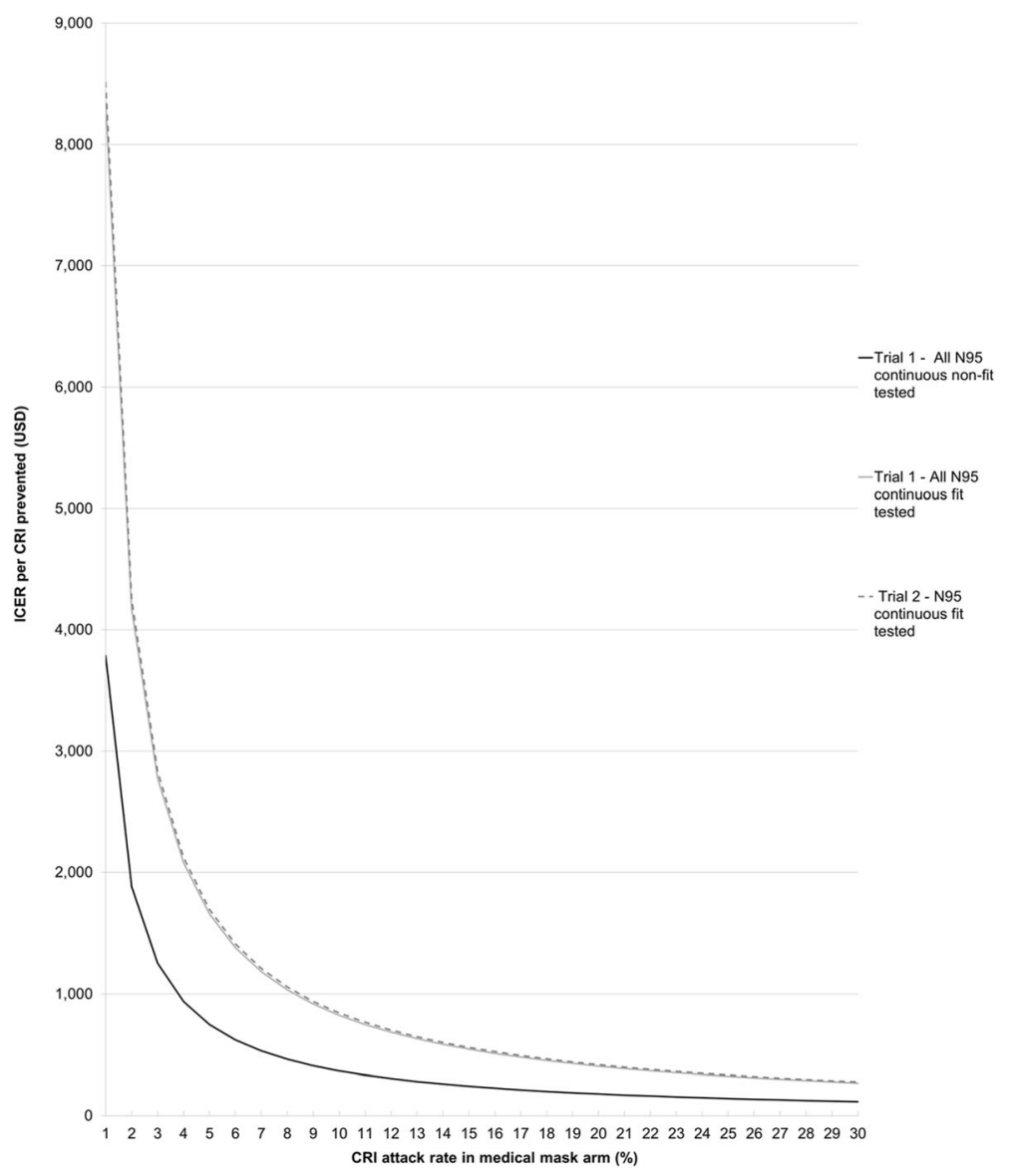

Fig. 3 Sensitivity analysis on the incremental cost-effectiveness ratio (ICER) based on variation in the attack rate in the medical mask arm. Variation in the clinical respiratory illness (CRI) attack rates in this arm represent potential seasonal differences in transmission. Results are for Beijing Trial 1 (2008/09) and Trial 2 (2009/10). Note: the lines for Trial 1 - All N95 continuous fit tested and Trial 2 - N95 continuous fit tested overlap

compared to medical masks was found to be substantially lower in high attack rate seasons (Fig. 3). It is important that this seasonal variation is accounted for when evaluating the cost-effectiveness of influenza prevention measures [23].

Whilst the results of our study are indicative of costeffectiveness, economic evaluations are not usually seen as transferable between settings. Mask/respirator interventions in HCWs need to be evaluated for countries separately to account for inter-country variations in factors such as intervention acceptability [24, 25], healthcare costs and productivity costs. Variation within countries is also possible and hence the results of this study which only includes trial data from Beijing hospitals may not be generalisable to all settings in China.

China has comparatively high cultural acceptability of mask/respirator use compared to western countries [26]. Furthermore, a study of Beijing HCWs regarding $\mathrm{A}(\mathrm{H} 1 \mathrm{N1})$ pdm09, suggests that some HCWs in this setting may continue to attend work with symptoms of influenza like illness [27]. This may partially explain the relatively low levels of absenteeism for HCWs with CRI in the trials. The low mean healthcare costs for CRI in both trials may have been due to the relatively modest influenza seasons and low levels of healthcare seeking by staff $[14,15]$. The existing economic studies on masks/respirators have suggested that the interventions were likely to be cost-effective in the high income settings they examined [28-32]. However, it is difficult to compare the results of our evaluation to these previous high income setting studies as they often did not report results in an easily comparable format (e.g. cost per case prevented) and most did not use clinical trial efficacy data to inform their analyses [33].

A limitation of the original trials was the 28 day duration $[14,15]$ meaning that the results may not translate to longer term interventions which may have different adherence levels. A limitation of our analysis is that the effect of the interventions on CRI rates in the patients or family members of HCWs could not be included due to the absence of data. The exclusion of these factors will make our results more conservative. $\mathrm{HCW}$ s are 
Table 3 Sensitivity analysis on the ICER based on variation in intervention efficacy and costs for Beijing Trial 1 (2008/09) and Trial 2 (2009/10)

\begin{tabular}{|c|c|c|c|c|c|}
\hline \multirow[t]{2}{*}{ Parameter input value } & & \multicolumn{2}{|l|}{ Trial 1} & \multirow{2}{*}{$\begin{array}{l}\text { Trial } 2 \\
\text { Continuous N95 fit tested } \\
2014 \text { USD, (RMB) }\end{array}$} & \multirow[t]{2}{*}{ Source } \\
\hline & & $\begin{array}{l}\text { Continuous All N95 } \\
\text { (without fit testing cost) } \\
2014 \text { USD, (RMB) }\end{array}$ & $\begin{array}{l}\text { Continuous All N95 } \\
\text { (with fit testing cost) } \\
2014 \text { USD, (RMB) }\end{array}$ & & \\
\hline Base case results & - & 549 (3404) & $1224(7589)$ & 489 (3032) & - \\
\hline \multicolumn{6}{|c|}{ Intervention efficacy vs. Medical Mask } \\
\hline Lowest effectiveness $^{a}$ & $\begin{array}{l}\text { 14\% (Trial 1) } \\
39 \% \text { (Trial 2) }\end{array}$ & $2473(15333)$ & $5462(33864)$ & $1038(6436)$ & $\begin{array}{l}{[14]} \\
{[15]}\end{array}$ \\
\hline Highest effectiveness ${ }^{a}$ & $\begin{array}{l}83 \% \text { (Trial 1) } \\
79 \% \text { (Trial 2) }\end{array}$ & 407 (2523) & $911(5648)$ & $376(2331)$ & $\begin{array}{l}{[14]} \\
{[15]}\end{array}$ \\
\hline \multicolumn{6}{|l|}{ Alternative costs } \\
\hline Max treatment costs & $\$ 525^{\mathrm{b}}(3255 \mathrm{RMB})$ & $30(186)$ & 704 (4365) & Cost saving ${ }^{b}$ & [22] \\
\hline Min treatment costs & $\$ 0(0 \mathrm{RMB})$ & $555(3441)$ & $1230(7626)$ & $492(3050)$ & Assumption \\
\hline N95 purchase cost doubled & $\$ 1.58$ (8 RMB) & $1313(8141)$ & $1988(12326)$ & 825 (5115) & Assumption \\
\hline N95 purchase cost halved & $\begin{array}{l}\$ 0.40 \\
(2 \mathrm{RMB})\end{array}$ & $167(1035)$ & $842(5220)$ & $321(1984)$ & Assumption \\
\hline
\end{tabular}

${ }^{a}$ High and low efficacy estimates calculated from the confidence intervals generated for the clustering and confounder adjusted results from Trial 1 and 2 respectively ${ }^{b}$ This severe illness treatment cost for each CRI case [22] is unlikely except in a highly pathogenic influenza epidemic/pandemic where an average case requires substantial healthcare treatment

known to transmit various types of nosocomial infections to patients [34] and the literature indicates that there are likely to be substantial benefits if the number of patients with CRI is reduced [22]. For example, the benefits of preventing HCW infection transmission through vaccination have been observed in long-term care facilities that found an associated decrease in mortality in their elderly residents [35-37]. The difference in mean direct healthcare costs per HCW with CRI between the trials (i.e. US $\$ 5.45$ [34 RMB] in Trial 1 and US \$2.60 [16 RMB] in Trial 2) may partly reflect variation in the thoroughness of the sick follow-up data collection between the trials. Another potential limitation of this study is that stochastic uncertainty was not directly explored using the individual level data from the trials [21]. Instead, we adopted a decision-model based approach using clinical trial data to inform input parameter values and explored the uncertainty of these values in deterministic sensitivity analyses. This approach facilitated a focus on forms of uncertainty unrelated to sampling, such as the potential inter-year variation in the CRI attack rate. Finally, as data on quality of life were not collected in the trial we chose to focus the economic analysis on the primary trial outcome (CRI). This limits the ability to compare the value for money offered against other interventions.

\section{Conclusions}

This economic evaluation is the first economic analysis of mask/respirator interventions to be conducted for a middle income setting and it is one of the first to make use of clinical trial evidence $[14,15]$. This evaluation provides valuable evidence that can be used by decision makers to help assess the costs and benefits of alternative $\mathrm{HCW}$ mask/respirator protection strategies. The determination of cost-effectiveness will depend on the willingness to pay to prevent a CRI case in a HCW and this varies between countries and is not easily transferrable between different settings. The extent to which a decision maker is likely to focus on cost-effectiveness evidence when it comes to $\mathrm{HCW}$ protection will in part depend on the seriousness of the infections being prevented $[33,38]$. In the case of a highly pathogenic pandemic, respirator use in HCWs would likely be a cost-effective intervention.

\section{Abbreviations}

CDC: Centres for Disease Control and Prevention; CRI: Clinical respiratory illness; HCW: Healthcare worker; ICER: Incremental cost-effectiveness ratio; WHO: World Health Organization

\section{Acknowledgements}

We would like to thank Abrar Chughtai for his contribution to the study.

\section{Funding}

The work was supported by the NHMRC Centre for Research Excellence Integrated Systems for Epidemic Response (ISER), grant number APP1107393. $3 \mathrm{M}$ provided supplies of respirators and medical masks for the original investigator-driven trials in China.

\section{Availability of data and materials}

The data used in this study that were not published in the Beijing mask/ respirator HCW clinical trials $[14,15]$ were obtained from the researchers who led these studies. Enquiries regarding these data should be directed to Dr. Holly Seale (h.seale@unsw.edu.au). 


\section{Authors' contributions}

CRM conceived the study. ATN supervised the analysis. SM implemented the model, conducted the analysis and drafted the initial manuscript with input from ATN and CRM. XW, QW, PY and HS assisted with parameterisation of the model and/or the original trial data collection. All authors reviewed the manuscript and approved the final draft.

\section{Ethics approval and consent to participate}

This economic evaluation was approved by the Medical and Community Human Research Ethics Advisory Panel of the University of New South Wales, Australia (2013-7-54). The original Trial 1 and Trial 2 study protocols were approved by the Institutional Review Board and Human Research Ethics Committee of the Beijing Ministry for Health. The Trial 2 study protocol was also approved by the Human Research Ethics Committee of the University of New South Wales, Australia. Trial 1 and Trial 2 were registered in the Australian New Zealand Clinical Trials Registry (ACTRN12609000257268, ACTRN 12609000778280) http://www.anzctr.org.au.

\section{Consent for publication}

Not applicable.

\section{Competing interests}

RM has conducted several investigator-driven trials of respirators and medical masks, one of which was funded by an Australian Research Council Linkage Grant, where the industry partner was $3 \mathrm{M}$, a manufacturer of personal protective equipment. HS, ATN, QW, PY and XW were also involved in this research. $3 \mathrm{M}$ also provided supplies of respirators and medical masks for the investigator-driven trials in healthcare workers in China.

\section{Publisher's Note}

Springer Nature remains neutral with regard to jurisdictional claims in published maps and institutional affiliations.

\section{Author details}

'School of Public Health and Community Medicine, The University of New South Wales, Sydney, NSW 2052, Australia. ${ }^{2}$ National Centre for Immunisation Research and Surveillance of Vaccine Preventable Diseases (NCIRS), University of Sydney, Westmead, NSW, Australia. ${ }^{3}$ The Beijing Centre for Disease Control and Prevention, Beijing, China.

\section{Received: 10 September 2016 Accepted: 23 June 2017} Published online: 03 July 2017

\section{References}

1. Kuster SP, Shah PS, Coleman BL, Lam P-P, Tong A, Wormsbecker A, et al. Incidence of influenza in healthy adults and healthcare workers: a systematic review and meta-analysis. PLOS ONE. 2011;6:10.e26239. doi:10.1371/journal.pone.0026239.

2. Nishiyama A, Wakasugi N, Kirikae T, Quy T, Ha le D, Ban W, et al. Risk factors for SARS infection within hospitals in Hanoi, Vietnam. Jpn J Infect Dis. 2008;61(5):388-90.

3. Chung JS, Ling ML, Seto WH, Ang BSP, Tambyah PA. Debate on MERS-CoV respiratory precautions: surgical mask or N95 respirators? Singap Med J. 2014;55(6):294-7.

4. Chughtai AA, Seale H, Macintyre CR. Availability, consistency and evidencebase of policies and guidelines on the use of mask and respirator to protect hospital health care workers: a global analysis. BMC Res Notes. 2013;6:216. doi:10.1186/1756-0500-6-216.

5. Weber A, Willeke K, Marchioni R, Myojo T, McKay R, Donnelly J, et al. Aerosol penetration and leakage characteristics of masks used in the health care industry. Am J Infect Control. 1993;21(4):167-73.

6. Shine Kl, Rogers B, Goldfrank LR. Novel H1N1 influenza and respiratory protection for health care workers. N Engl J Med 2009. 2009;361(19):1823-5.

7. IOM (Institute of Medicine). Preventing transmission of pandemic influenza and other viral respiratory diseases: Personal protective equipment for healthcare personnel. Update 2010. In: Larson E, Liverman CT, editors. Committee on Personal Protective Equipment for Healthcare Personnel to Prevent Transmission of Pandemic Influenza and Other Viral Respiratory Infections: Current Research Issues. Washington, DC: The National Academies Press. 2011.
8. The National Institute for Occupational Safety and Health (NIOSH): DHHS (NIOSH) Publication Number 96-101 - Certified Under 42 CFR 84. In: NIOSH Guide to the Selection and Use of Particulate Respirators. NIOSH. 1996. https://www.cdc.gov/niosh/docs/96-101/. Accessed 18 Sep 2014.

9. Centres for Disease Control and Prevention. Prevention Strategies for Seasonal Influenza in Healthcare Settings. (http://www.cdc.gov/flu/ professionals/infectioncontrol/healthcaresettings.htm.) 2013. Accessed 4 September 2014.

10. World Health Organization. Epidemic and pandemic prone acute respiratory diseases - infection prevention and control in health care. 2014. http:// www.who.int/csr/bioriskreduction/infection_control/publication/en/. Accessed 11 April 2015.

11. World Health Organization. Infection prevention and control during health care for confirmed, probable, or suspected cases of pandemic (H1N1) 2009 virus infection and influenza like illnesses. Geneva: World Health Organization; 2009. http://www.who.int/csr/resources/publications/cp150_ 2009_1612_ipc_interim_guidance_h1n1.pdf. Accessed 11 April 2015

12. Centres for Disease Control and Prevention. Interim Guidance on Infection Control Measures for 2009 H1N1 Influenza in Healthcare Settings, Including Protection of Healthcare Personnel. In: H1N1 Flu Clinical and Public Health Guidance. 2010. http://www.cdc.gov/h1n1flu/guidelines_infection_control. htm. Accessed 11 April 2015.

13. Maclntyre CR, Chughtai AA. Facemasks for the prevention of infection in healthcare and community settings. BMJ. 2015;350. doi:http://dx.doi.org/10.1136/bmj.h694.

14. Maclntyre CR, Wang Q, Cauchemez S, Seale H, Dwyer DE, Yang P, et al. A cluster randomized clinical trial comparing fit-tested and non-fit-tested N95 respirators to medical masks to prevent respiratory virus infection in health care workers. Influenza Other Respir Viruses. 2011;5(3):170-9.

15. Maclntyre CR, Wang Q, Seale H, Yang P, Shi W, Gao Z, et al. A randomized clinical trial of three options for N95 respirators and medical masks in health workers. Am J Respir Crit Care Med. 2013;187(9):960-6.

16. Carrat F, Sahler C, Rogez S, Leruez-Ville M, Freymuth F, Le Gales C, et al. Influenza burden of illness: estimates from a national prospective survey of household contacts in France. T JAMA. 2002;288:23:2946.

17. Knott $\mathrm{P}$, Gorman T. Respirator Fit Testing. In: $3 \mathrm{M}$ TechUpdate. $3 \mathrm{M}$ Australia. 2008. http://multimedia.3m.com/mws/mediawebserver?mwsld= SSSSSuH8gc7nZxtUn8_ZPxt1evUqe17zHvTSevTSeSSSSSS\%2D-\&fn= Respirator\%20Fit\%20Testing.pdf. Accessed 8 Aug 2014.

18. World Health Organization. Undertaking a study using GCEA. In: T. TanTorres Edejer RB, T. Adam, R. Hutubessy, A. Acharya, D.B. Evans, editors. WHO guide to cost-effectiveness analysis. Geneva: World Health Organization; 2003. p. 17-27.

19. Beijing pharmaceutical sunshine procurement platform. Beijing pharmaceutical sunshine procurement platform, Beijing. http://210.73.89.76/ ServiceSelect/GetServiceSelectList. Accessed 12 April 2017.

20. National Bureau of Statistics China. Average Wage of Employed Persons in Urban Units by Sector (2014). In: China Statistical Yearbook 2015. http:// www.stats.gov.cn/tjsj/ndsj/2015/indexeh.htm. Accessed 27 April 2017.

21. Drummond M, Sculpher MJ, Torrance GW, O'Brien BJ, Stoddart GL. Methods for the economic evaluation of health care programmes. 3rd ed. Oxford: Oxford University Press; 2005.

22. Zhou L, Situ S, Huang T, Hu S, Wang X, Zhu X, et al. Direct Medical Cost of Influenza-Related Hospitalizations among Severe Acute Respiratory Infections Cases in Three Provinces in China. PLOS ONE. 2013;8:5: e63788. doi:10.1371/journal.pone.0063788.

23. Newall AT, Dehollain JP, Creighton P, Beutels P, Wood JG. Understanding the cost-effectiveness of influenza vaccination in children: methodological choices and seasonal variability. PharmacoEconomics. 2013;31(8):693-702.

24. Aiello AE, Perez V, Coulborn RM, Davis BM, Uddin M, Monto AS. Facemasks, hand hygiene, and influenza among young adults: A randomized intervention trial. PLOS ONE. 2012;7:1. e29744. doi:10.1371/journal.pone. 0029744.

25. Chor JSY, Pada SK, Stephenson I, Goggins WB, Tambyah PA, Medina M, et al. Differences in the compliance with hospital infection control practices during the 2009 influenza H1N1 pandemic in three countries. J Hos Infect. 2012;81(2):98-103.

26. Maclntyre CR, Cauchemez S, Dwyer DE, Seale H, Cheung P, Browne G, et al. Face mask use and control of respiratory virus transmission in households. Emerg Infect Dis. 2009;15(2):233-41. 
27. Seale $H$, Wang $Q$, Yang $P$, Dwyer DE, Zhang Y, Wang X, et al. Hospital health care workers' understanding of and attitudes toward pandemic influenza in Beijing. Asia Pac J Public Health. 2012;24(1):39-47.

28. Dan YY, Tambyah PA, Sim J, Lim J, Hsu LY, Chow WL, et al. Costeffectiveness analysis of hospital infection control response to an epidemic respiratory virus threat. Emerg Infect Dis. 2009;15(12):1909-16.

29. Cahill BP, Collins RD, Jurko RC, Zivic TR, Crowther KG, Haimes YY. Collaborative risk-based preparedness for pandemic influenza in southeastern Virginia. In: proceedings of the 2008 IEEE systems and Information engineering design symposium, University of Virginia, Charlottesville. 2008. p. 323-328.

30. Tracht SM, Del Valle SY, Edwards BK. Economic analysis of the use of facemasks during pandemic (H1N1) 2009. J Theor Biol. 2012;300:161-72.

31. Jones RM, Adida E. Selecting nonpharmaceutical interventions for influenza. Risk Anal. 2013;33(8):1473-88.

32. Chen SC, Liao CM. Cost-effectiveness of influenza control measures: a dynamic transmission model-based analysis. Epidemiol Infect. 2013;141(12):2581-94.

33. Mukerji $S$, Maclntyre CR, Newall AT. Review of economic evaluations of mask and respirator use for protection against respiratory infection transmission. BMC Infect Dis. 2015;15(1):1-8.

34. Weber DJ, Rutala WA, Schaffner W, Weber DJ, Rutala WA, Schaffner W. Lessons learned: Protection of healthcare workers from infectious disease risks. Crit Care Med. 2010;38: 8Suppl:S306-14. doi:10.1097/CCM. 0b013e3181e69ebd.

35. Carman WF, Elder AG, Wallace LA, McAulay K, Walker A, Murray GD, et al. Effects of influenza vaccination of health-care workers on mortality of elderly people in long-term care: a randomised controlled trial. Lancet. 2000;355(9198):93-7.

36. Lemaitre M, Meret T, Rothan-Tondeur M, Belmin J, Lejonc J-L, Luquel $L$, et al. Effect of influenza vaccination of nursing home staff on mortality of residents: a cluster-randomized trial. J Am Geriatr Soc. 2009;57(9):1580-6.

37. Hayward AC, Harling R, Wetten S, Johnson AM, Munro S, Smedley J, et al. Effectiveness of an influenza vaccine programme for care home staff to prevent death, morbidity, and health service use among residents: cluster randomised controlled trial. BMJ. 2006; 333 doi:http://dx.doi.org/10.1136/ bmj.39010.581354.55.

38. Branch-Elliman W, Savor Price C, McGeer A, Perl TM. Protecting the frontline: designing an infection prevention platform for preventing emerging respiratory viral illnesses in healthcare personnel. Infect Control Hosp Epidemiol. 2015;36(3):336-45.

\section{Submit your next manuscript to BioMed Central and we will help you at every step:}

- We accept pre-submission inquiries

- Our selector tool helps you to find the most relevant journal

- We provide round the clock customer support

- Convenient online submission

- Thorough peer review

- Inclusion in PubMed and all major indexing services

- Maximum visibility for your research

Submit your manuscript at www.biomedcentral.com/submit

C) Biomed Central 